\title{
A General Approach to Indoles: Practical Applications for the Synthesis of Highly Functionalized Pharmacophores
}

\author{
Jeffrey T. Kuethe
}

\begin{abstract}
The development of a long-term manufacturing route to a potent and selective KDR kinase inhibitor has led to the discovery of several novel methodologies for the general synthesis of indoles. The key transformations involved addition of a trimethylsilylnitro benzene to an aromatic aldehyde which afforded the key nitroalcohol intermediate. Oxidation of the nitroalcohol intermediate led to a nitroketone; whereas, elimination afforded exclusively a trans-nitrostyrene. Reductive cyclization gave the target compounds in excellent overall yield from readily available bulk chemicals. Application of this methodology has led to the synthesis of highly functionalized pharmacophores including other KDR kinase inhibitors, biindoles and tjipanazole natural products, indolo[2,3-a]pyrrolo [3,4-c]carbazoles, indole-4-carboxylic amides, N-hydroxyindoles, and 2,3-dihydrobenzofurans.
\end{abstract}

Keywords: Dihydrobenzofuran $\cdot$ Indole $\cdot$ Nitrostyrene $\cdot$ Reductive cyclization

\section{Introduction}

The indole nucleus is arguably the most widely distributed heterocyclic ring system found in nature. Owing to the vast array of structurally diverse and biologically active indoles, it is not surprising that the indole nucleus is an important component in many pharmaceutical agents [1]. Substituted indoles have been referred to as 'privileged structures' since they are capable of binding to multiple receptors with a high degree of affinity [2]. The synthesis and functionalization of indoles continues to be a major area of focus for academic as well as industrial researchers, and numerous methods for their preparation have been developed [3][4]. Starting material availability and functional group compatibility often dictate which particular indole synthesis will be suitable. When particular substitution patterns remain difficult to obtain by standard indole-forming reactions, new methodologies emerge.

Tyrosine kinases are a class of enzymes believed to play a critical role in the signal transduction of a number of cellular functions and have been implicated in a wide range of diseases and conditions [5]. Angiogenesis is characterized by excessive activity of vascular endothelial growth factor (VEGF) leading to formation of blood vessels necessary for the support of tumor growth. The kinase insert domain receptor (KDR) is a tyrosine kinase that has a high affinity for VEGF. KDR is believed to be a primary mediator of tumor-induced angiogenesis; therefore, inhibition, modulation, or regulation of the KDR receptor may be useful in the prevention and treatment of tumor-induced angiogenesis and various other diseases including cancer, psoriasis, and hyper-immune responses. Merck has identified a number of potent and selective KDR inhibitors for the potential use in a range of cancer indications [6][7]. As part of a program to discover and develop inhibitors of KDR kinase activity, compound 1 was selected for preclinical and clinical development (Fig. 1). The key structural feature of $\mathbf{1}$ is the indol-2-yl- $1 H$-quinolin2-one ring system bearing a mesylpipera-

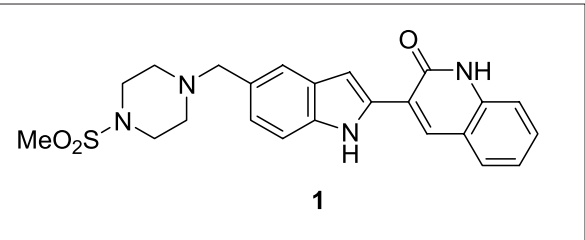

Fig. 1. zine moiety where the indolyl quinolinone ring system is the central pharmacophore. The development of a practical, long-term manufacturing route to 1 will be described as well as the evolution of a research program aimed at the application of novel methodologies for the preparation of other highly functionalized indoles and dihydrobenzofurans.

\section{The Problem and Approach}

Conventional approaches to 2-aryl indoles have typically relied upon either the classical Fischer indole synthesis [3][4] or cross coupling of 2-indolyl halides, boronic acids, stannanes, and silanes [8]. Although effective methods are now available for the preparation of 2-indolyl boronic acids and silanes [9], the major limitation with most of these approaches are the additional steps required for the preparation of the coupling partners to enter the palladiumcatalyzed reactions. The first generation synthesis of 1 relied on a highly efficient Suzuki-Miyaura cross-coupling between indolyl boronic acid 5 and 3-bromo- $1 \mathrm{H}$ quinolin-2-one 6 (Scheme 1) [10]. This approach provided $\mathbf{1}$ in seven linear steps and in 55\% overall yield, and the route suffered from costly starting materials (i.e. 5 and 6), required protection of the indole and piperazine moieties, and utilized an excess ( 1.5 equiv.) of 5 in the cross cou- 


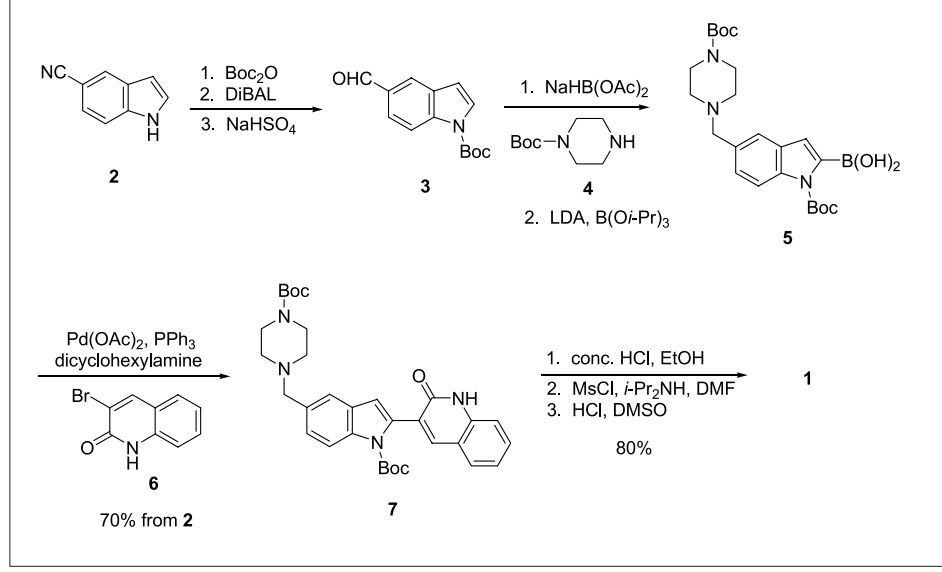

Scheme 1.

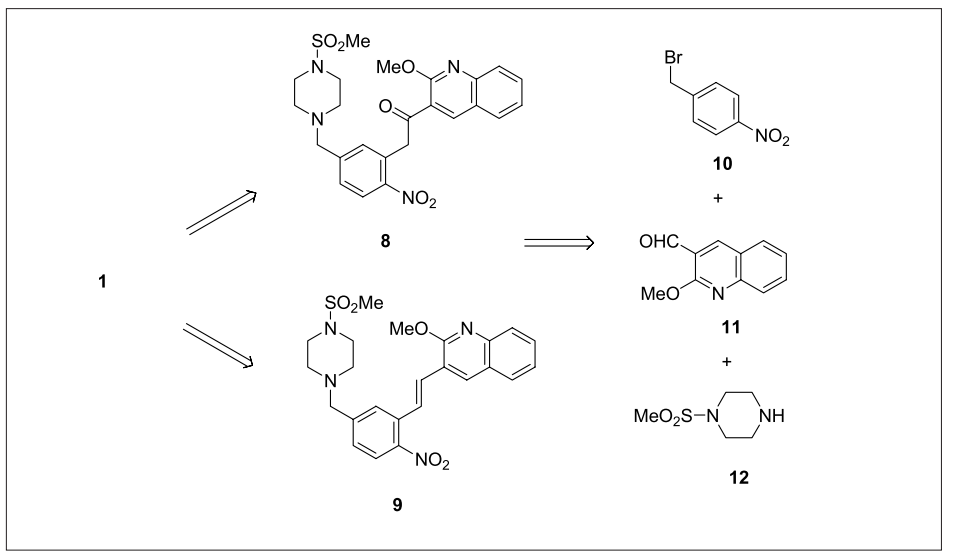

Scheme 2.

pling step. In addition, the poor solubility of the quinolin-2-one moiety of 7 and downstream intermediates made processing extremely difficult and necessitated the use of large reaction volumes. Therefore, an improved long-term, cost effective manufacturing route was required.

Retrosynthetic analysis of $\mathbf{1}$ revealed there may be a number of intriguing methods of constructing the indol-2-yl-quinolin-2-one ring system. Approaches which centered on formation of the indole ring as the key step for the preparation of $\mathbf{1}$ were particularly attractive. Reactions leading to increasing molecular complexity are important synthetic tools, and it was envisioned that construction of the indole ring as the key synthetic step would allow for the preparation of intermediates from readily available starting materials. Of the many routes investigated [11], the reductive cyclization of nitro ketone 8 or nitro styrene 9 offered the possibility of improved synthetic efficiency and would provide the indol-2-yl-quinolin-2-one ring system of $\mathbf{1}$ in fewer synthetic steps with better atom economy (Scheme 2). Due to the poor solubility properties associated with the $1 H$-quinolin-2-one ring system of 1 and all related intermediates, the readily available and easily hydrolyzed methoxyprotected quinoline $\mathbf{1 1}$ was utilized. This masked quinolinone protecting group became a key design feature and imparted a

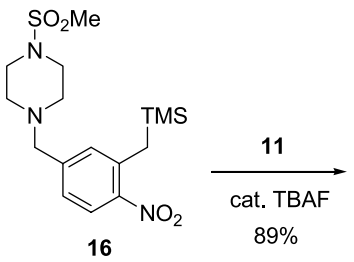

Scheme 3. significant degree of solubility to synthetic intermediates.

\subsection{Nitro Ketone Reductive Cyclization Route}

Reductive cyclization of 2-nitrobenzylcarbonyl compounds is one of the oldest methods for the construction of indoles and indolinones [1][3][4]. The reductive cyclization of 2-nitrobenzyl ketones has been carried out with a variety of reagents including $\mathrm{H}_{2} / \mathrm{Pd}, \mathrm{H}_{2} / \mathrm{RaNi}, \mathrm{SnCl}_{2}, \mathrm{Fe} / \mathrm{AcOH}$, $\mathrm{Zn} / \mathrm{AcOH}, \mathrm{TiCl}_{3} / \mathrm{NH}_{4} \mathrm{OAc}$, and $\mathrm{Na}_{2} \mathrm{~S}_{2} \mathrm{O}_{3}$ [1][4]. However, the availability of starting materials has severely limited the util- ity of this approach. Recent advances by the groups of Buchwald [12], Rawal [13], RajanBabu [14], and others [15] have given ready access to 2-nitrobenzyl ketones which are conveniently converted to substituted indoles. While these methods are noteworthy, there was still a need for alternative methods which provide highly functionalized 2-nitrobenzyl ketones and their subsequent conversion to indoles.

Our first goal was the development of an efficient high-yielding synthesis of nitroketone $\mathbf{8}$, and our approach was inspired by the unique versatility of nitrobenzenes due to their ability to serve as nucleophilic and electrophilic partners [16]. The synthesis of $\mathbf{8}$ began by alkylation of readily available 4-nitrobenzyl bromide 13 with 1methanesulfonlypiperazine 12 (Scheme 3) [17]. Reaction of $\mathbf{1 2}$ and $\mathbf{1 3}$ for $2 \mathrm{~h}$ in DMF in the presence of $\mathrm{K}_{2} \mathrm{CO}_{3}$ at room temperature afforded nitro derivative $\mathbf{1 4}$ in $95 \%$ isolated yield. Addition of trimethylsilylmethylmagnesium chloride $\mathbf{1 5}$ to a solution of 14 in THF at $-15{ }^{\circ} \mathrm{C}$ followed by oxidation of the resulting nitronate intermediate with DDQ [18] gave addition compound 16 in $85 \%$ yield. Alternatively, the oxidation could be carried out with $p$-chloranil and gave 16 in $83 \%$ yield. The corresponding workup of these reactions proved difficult to engineer on larger scale $(>10 \mathrm{~g})$ due to difficulty in removing DDQ or $p$-chloranil by-products. After extensive experimentation it was discovered that the oxidation of the nitronate intermediate was cleanly achieved with aqueous $1 \mathrm{~N}$ iodine solution which greatly simplified the workup and gave 16 in $85 \%$ yield. The higher purity of the crude stream of $\mathbf{1 6}$ allowed for its use in the subsequent reactions without the need for chromatography or further purification.

Treatment of a mixture of $\mathbf{1 6}$ and aldehyde 11 with a catalytic amount of TBAF furnished alcohol $\mathbf{1 7}$ in $89 \%$ yield [19]. Alcohol 17 was not isolated but used directly in the oxidation step without further
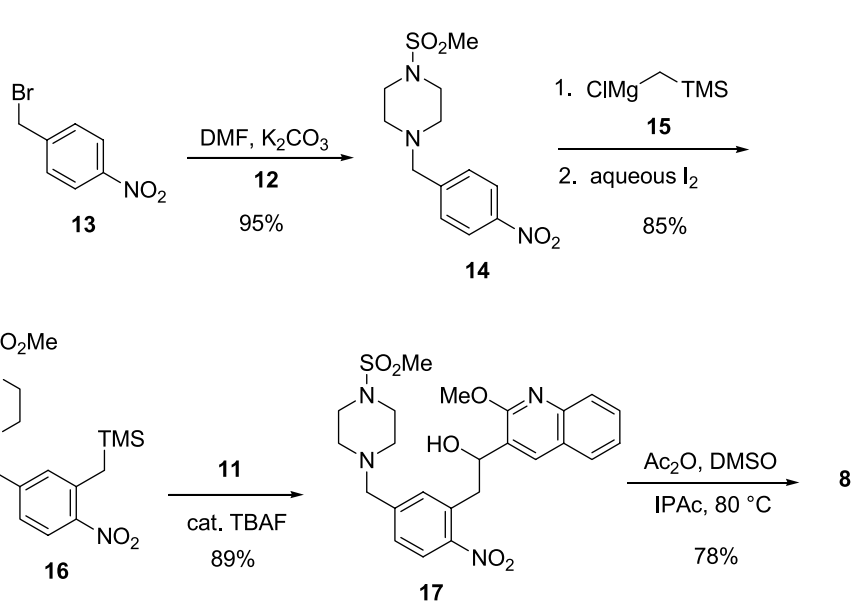


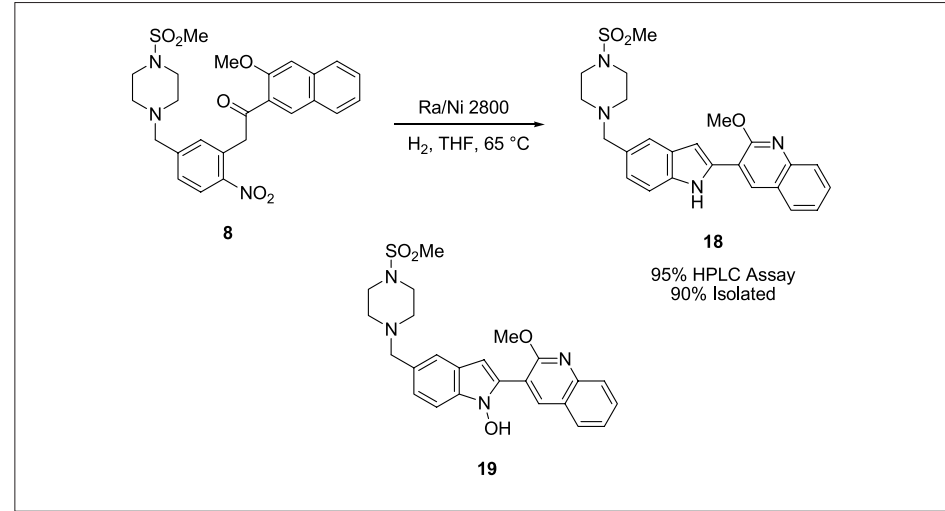

Scheme 4.

purification as a stream in isopropyl acetate (IPAc). Oxidation of $\mathbf{1 7}$ with $\mathrm{Ac}_{2} \mathrm{O} / \mathrm{DMSO}$ in IPAc at $80^{\circ} \mathrm{C}$ gave ketone 8 which could be crystallized from the crude reaction mixture in $78 \%$ yield [20].

The reductive cyclization of $\mathbf{8}$ to indole 18 was accomplished under highly optimized conditions employing hydrogenation over Raney nickel in order to minimize the formation of hydroxyindole 19 (Scheme 4) [21]. Under most conditions screened, hydroxindole 19 was the major product even upon prolonged reaction and the addition of excess catalyst [21]. The optimal conditions for the conversion of $\mathbf{8}$ to $\mathbf{1 8}$ involved the use of $\mathbf{4 0}$ wt $\%$ of $\mathrm{Ra} / \mathrm{Ni} 2800\left(\mathrm{H}_{2} \mathrm{O}\right), 40 \mathrm{psi}_{2}$, and $65{ }^{\circ} \mathrm{C}$ in THF for $7.5 \mathrm{~h}$ and gave $\mathbf{1 8}$ in $95 \%$ HPLC assay yield. There was no detectable amount of $\mathbf{1 9}$ in the crude reaction mixture under these conditions. The isolation of $\mathbf{1 8}$ was simply a matter of filtering the catalyst, concentrating the filtrate, and adding $\mathrm{MeOH}$, which precipitated the product in analytically pure form and in $90 \%$ isolated yield.

\subsection{Nitro Styrene Reductive Cyclization Route}

The widespread use of ortho-nitrostyrenes as synthetically useful intermediates has been limited by available methods for their preparation. Traditional approaches have relied on Wittig reactions of either 2-nitrobenzaldehydes or 2-nitrophosphonium and phosphonate salts [22]. Alternatively, cross-coupling approaches involving 2-halonitrobenzenes or 2-nitrophenylstannanes have received considerable attention as an attractive method for the preparation of a range of ortho-nitrostyrenes [23]. Although each of these approaches offer certain advantages, they often require multiple steps for the construction of the appropriate starting materials and generally require purification by chromatography. In addition, these strategies have a high environmental burden since they suffer from poor atom economy and generate a significant amount of phosphorous or tin by-products.

The reductive cyclization of aromatic nitrostyrene compounds for the formation pact [23][26][27]. of indoles has received considerable attention since the pioneering work of Cadogan et al. [24] and Sundberg et al. [25] who first described the formation of indoles via deoxygenation of aromatic nitrocompounds with trivalent phosphorus compounds (typically triethyl phosphite). While the Cadogan/Sundberg reaction is broad in scope, the extreme reaction conditions $\left(>150^{\circ} \mathrm{C}\right)$, formation of both N-hydroxy- and N-ethoxyindole byproducts, and the large amount of phosphorus waste render this transformation impractical for the process chemist. Transition metal catalyzed reductive cyclizations employing carbon monoxide as the stoichiometric reductant have recently emerged as a highly versatile method for the construction of indoles due to superior yields, diminished amounts of reaction byproducts, and favorable environmental im-

The preparation and reductive cyclization of nitrostyrene 9 is outlined in Scheme 5. Treatment of crude alcohol 17 with TFAA followed by elimination of the corresponding trifluoroacetate with DBU at $60{ }^{\circ} \mathrm{C}$, in a one-pot operation, afforded exclusively trans-nitrostyrene 9 in $80 \%$ yield after direct crystallization from the crude reaction mixture. There was no detectable amount of any cis-nitrostyrene formed in the reaction mixture. The use of DBU for the elimination of the trifluoroacetate intermediate was also found to be crucial. When other amine bases were employed, little conversion to 9 was observed, and the use of aqueous bases resulted in hydrolysis and alcohol $\mathbf{1 7}$ was re-isolated.

The reductive cyclization of 9 was extensively investigated with the aid of a parallel pressure reactor (PPR) in which optimization of all the reaction parameters (catalyst, ligand, solvent, temperature, pressure) could be conducted in an extremely rapid fashion [26]. The optimized reaction conditions employed $0.1 \mathrm{~mol} \% \mathrm{Pd}(\mathrm{TFA})_{2}$, $0.7 \mathrm{~mol} \%$ 3,4,7,8-tetramethylphenanthroline (TMP) in DMF at $80{ }^{\circ} \mathrm{C}$, and 15 psi $\mathrm{CO}$ to give $\mathbf{1 8}$ in $98 \%$ HPLC assay yield. The isolation of $\mathbf{1 8}$ involved filtration of the catalyst and addition of $\mathrm{MeOH}$ to provide $\mathbf{1 8}$ in $95 \%$ yield.

The deprotection of the masked quinolin-2-one moiety of $\mathbf{1 8}$, prepared by either reductive cyclization of nitroketone 8 (Scheme 4) or nitrostyrene 9 (Scheme 5) was accomplished in a straightforward manner under acidic conditions. Reaction of $\mathbf{1 8}$ with concentrated $\mathrm{HCl}$ in DMF at 70 ${ }^{\circ} \mathrm{C}$ followed by the addition of IPA as an anti-solvent gave the crystalline KDR kinase inhibitor $\mathbf{1}$ as the desired $\mathrm{HCl}$ salt in quantitative yield. Compound $\mathbf{1}$ was prepared in six synthetic steps from readily available bulk chemicals in $56 \%$ overall yield for the nitroketone route and $60 \%$ overall yield for the nitrostyrene route. Due the use of 40 $\mathrm{wt} \% \mathrm{Ra} / \mathrm{Ni}$ and the presence of an oxidation step in the nitroketone route, the higher yielding nitrostyrene route was selected as the long-term manufacturing route for the preparation of $\mathbf{1}$.

\section{Application to Other KDR Kinase Inhibitors}

Prior to the finalization of the manufacturing route to $\mathbf{1}$, the above methodology was also utilized in the preparation of KDR kinase inhibitor 24 (Scheme 6) [28]. For example, addition of trimethylsilylmethylmagnesium chloride $\mathbf{1 5}$ to a solution of $\mathbf{2 0}$ [29] followed by oxidation with aqueous iodine afforded $\mathbf{2 1}$ in $83 \%$ yield. Treatment of a mixture of $\mathbf{2 1}$ and chloroquinoline $\mathbf{2 2}$ with a catalytic amount of TBAF furnished the 


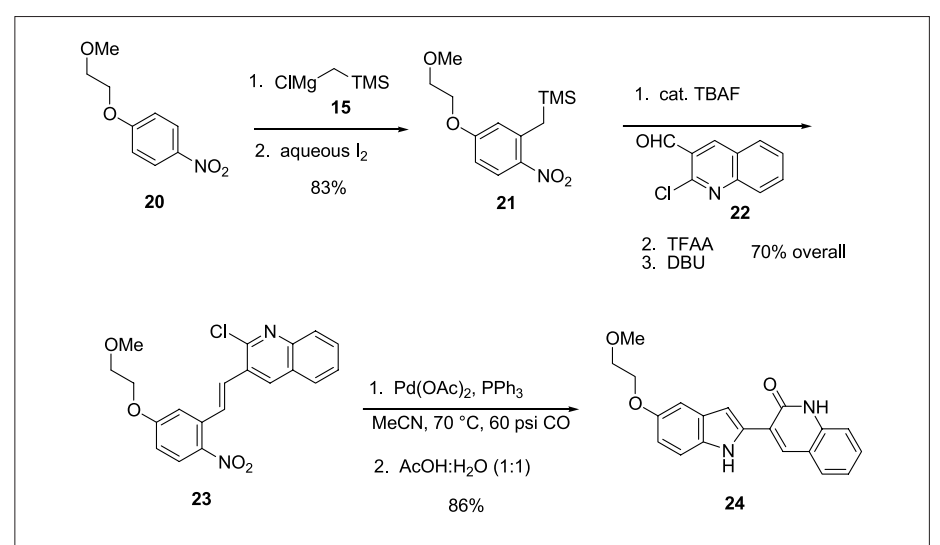

Scheme 6

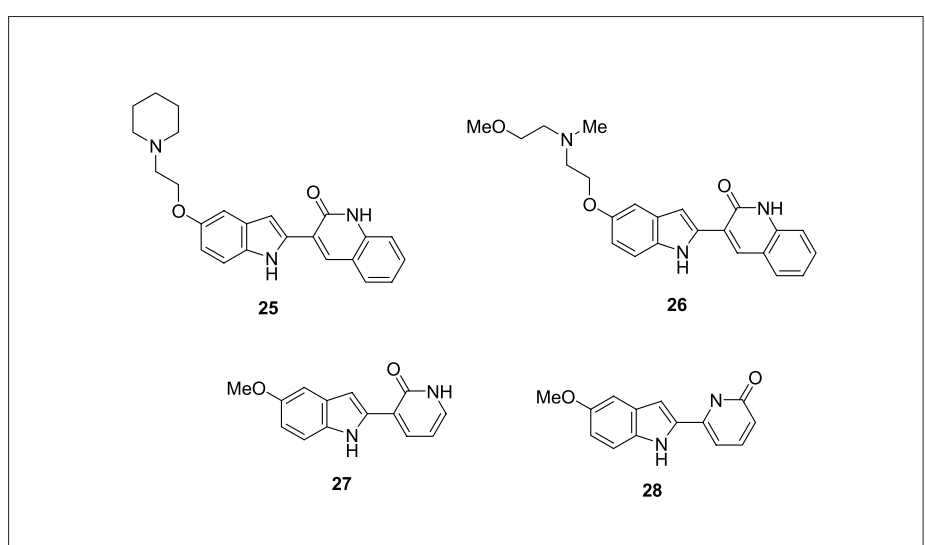

Fig. 2.

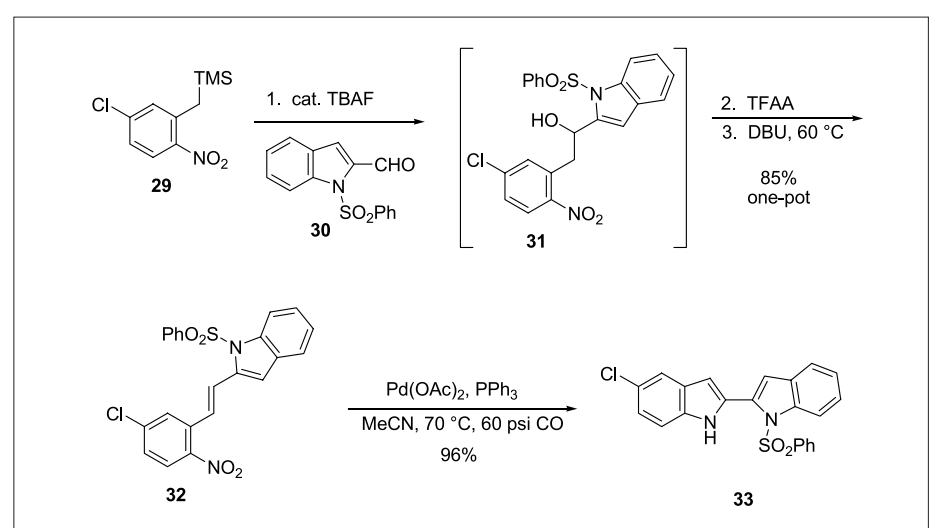

Scheme 7.

desired alcohol which was used crude in the elimination reaction without purification. Reaction with TFAA followed by elimination of the trifluoroacetate intermediate with DBU gave nitrostyrene $\mathbf{2 3}$ in $\mathbf{7 0 \%}$ overall yield from 21. Palladium-catalyzed reductive cyclization under Söderberg conditions (6 mol\% $\mathrm{Pd}(\mathrm{OAc})_{2}, 24 \mathrm{~mol} \% \mathrm{PPh}_{3}, \mathrm{CO}$ (6 atm), $70{ }^{\circ} \mathrm{C}$ ) [23] gave the corresponding indole in $94 \%$ yield. The quinolinone functionality was unmasked by hydrolysis of the chloroquinoline in 1:1 AcOH/water [7] and gave 24, which crystallized from the crude reaction mixture and was isolated in $91 \%$ yield. This same sequence of transformations was also successfully employed in the preparation of KDR kinase inhibitors 25-28 (Fig. 2) [28].

\section{Preparation of Indolo[2,3-a] carbazole Aglycons, Glycosides, and Indigo Azines}

The indolo[2,3-a]carbazole ring system constitutes the core skeleton of a family of structurally unique natural products possessing a wide range of biological activity [30]. Indolocarbazole glycosides with either one or two glycosidic linkages have been shown to be potent inhibitors of protein kinase $\mathrm{C}$ and topoisomerases and exhibit antitumor activity [30][31]. In addition, the aglycons have been shown to be potent and selective inhibitors of human cytomegalovirus [32]. The potency and selectivity of the indolocarbazoles depends on the arrangement of substituents about the aglycon as well as the nature of the carbohydrate moiety. Often the aromatic substituents are displayed in an unsymmetrical manner, which presents a formidable challenge to current synthetic methods. As an outgrowth of the KDR program, the ability to assemble highly functionalized 2-arylindoles rapidly from readily available starting materials prompted us to investigate this methodology for the preparation of unsymmetrical 2,2'-biindoles and their elaboration of indolo[2,3a]carbazole aglycons and glycosides [33].

The first challenge was preparation of the ortho-nitrostyrenes. Reaction of a mixture of the known TMS-nitro compound 29 [18] and indole carboxaldehyde $\mathbf{3 0}$ with a catalytic amount of TBAF afforded the desired alcohol $\mathbf{3 1}$ which was not isolated (Scheme 7). Direct addition of TFAA to the reaction mixture was followed by elimination of the corresponding trifluoroacetate with DBU at $60{ }^{\circ} \mathrm{C}$ and afforded exclu- sively the highly crystalline trans-nitrostyrene 32 in $85 \%$ overall yield for the one-pot transformation. Reductive cyclization of $\mathbf{3 2}$ gave biindole 33 in $96 \%$ yield. The reaction sequence was general and provided access to an array of diversely substituted symmetrical and unsymmetrical nitrostyrenes and biindoles in modest to excellent yield for each synthetic step (Table 1).

With the biindoles in hand, our focus turned to the preparation of tjipanazole alkaloids I, D, B, and E (Scheme 8). While the preparation of the indolocarbazole ring system of the tjipanazole alkaloids from 2,2'-biindoles was unprecedented, an operationally trivial procedure for incorporation of the two-carbon fragment with the correct oxidation state was developed [34]. For example, reaction of biindoles 36 and 39 with (dimethylamino)-acetaldehyde diethyl acetal in acetic acid [35] provided tjipanazoles I (53) and D (54) in 79 and $71 \%$ yields respectively. In similar fashion, reaction of biindole $\mathbf{4 2}$ under the identical reaction conditions gave indolocarbazole $\mathbf{5 5}$ in $73 \%$ yield. This synthetic strategy was particularly noteworthy as it gave access to unsymmetrical indolocarbazole aglycons in just three synthetic operations from readily available starting materials.

The installation of the carbohydrate moieties and the completion of the total syntheses of tjipanazoles E and B was accomplished by glycosication of $\mathbf{3 9}$ in a biphasic mixture of MTBE and $45 \%$ aqueous $\mathrm{KOH}$ and Aliquat 336 followed by hydrogenation [36]. Reaction of 39 with $\alpha-D-$ glycolopyranosyl chloride (56) [36] under these conditions furnished tjipanazole E (57) as a single anomer in $77 \%$ overall yield from 39. In like fashion, tjipanazole B (59) was obtained as a single anomer from $\alpha$-D-xylopyranosyl chloride (58) [37] in $66 \%$ overall yield. The synthetic sequence outlined in Scheme 8 allowed for the first reported total syntheses of tjipanazoles E and B via the high-yielding, stereoselective 
glycosidation of the respective indolocarbazole aglycon.

Due to the pronounced physiological activities of many indolo[2,3-a]pyrrolo[3,4$c$ carbazoles, which continue to attract the synthetic efforts of academic and pharmaceutical researchers, our 2,2'-biindoles bearing a phenylsulfonyl group were examined as suitable substrates for the synthesis of unsymmetrical indolo[2,3-a]pyrrolo[3,4c]carbazoles (Scheme 9) [38]. It was reasoned that $\mathrm{N}$-sulfonylbiindoles would provide significant advantages in the [4+2] cycloaddition with various dienophiles due to the electron-withdrawing nature of the sulfonyl group, which would facilitate the formation of the [4+2] adducts by accelerating the rate of cyclization (i.e. 64 to 65). Reaction of $\mathbf{3 3}$ with N-benzylmalimide in chlorobenzene $\left(150{ }^{\circ} \mathrm{C}\right.$, sealed tube, 12 h) gave $\mathbf{6 1}$ as the single reaction product, which crystallized from the crude reaction mixture in $50 \%$ yield. Interestingly, the phenylsulfonyl group was absent from the isolated product. It was speculated that addition of the dienophile to the 3-position of

Table 1. Preparation of nitrostyrenes and biindoles

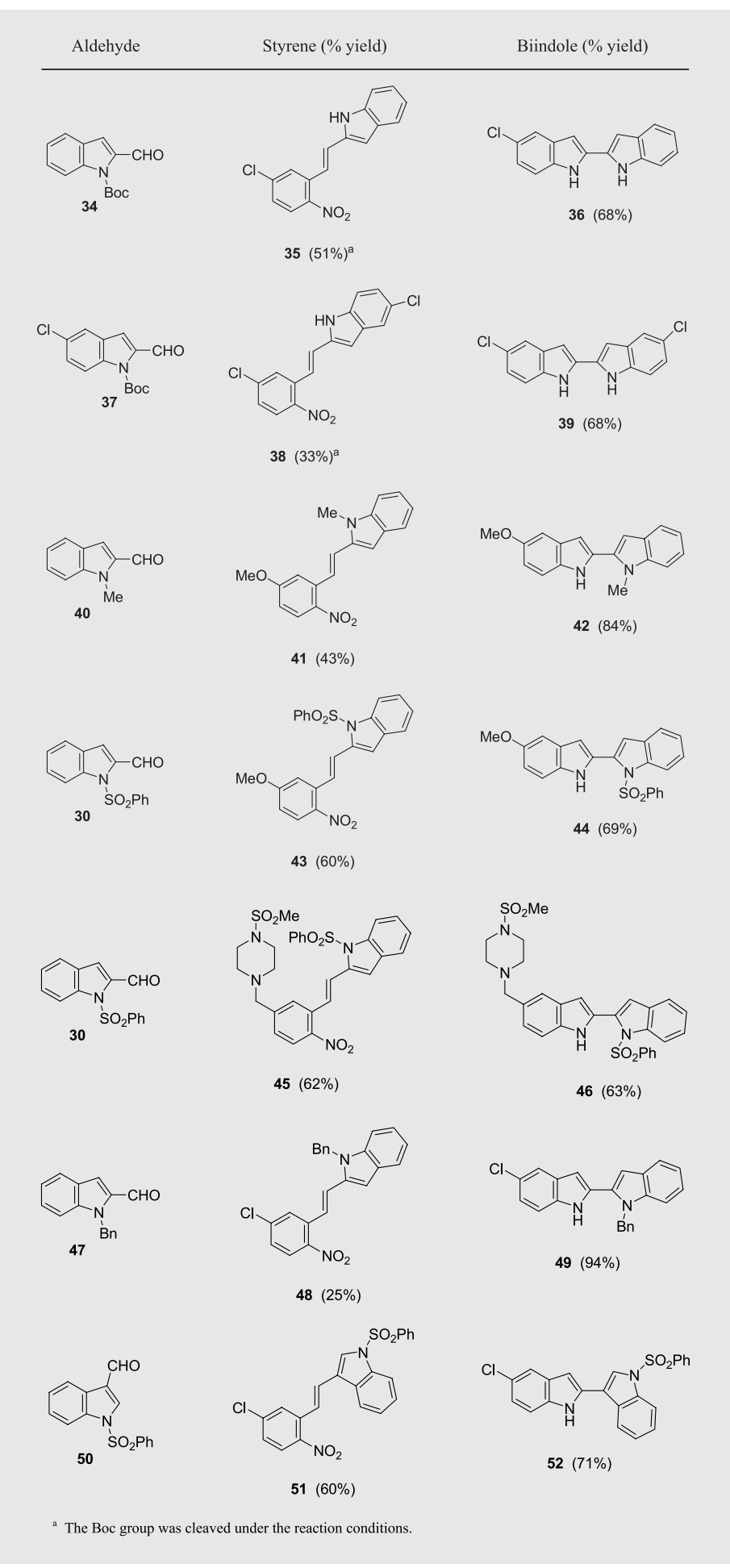

the unsubstituted indole ring gave intermediate 64. Rapid cyclization to $\mathbf{6 5}$, which is facilitated by the phenylsulfonyl group, was followed loss of the phenylsulfonyl group as part of the aromatization process. Dehydrogenation of $\mathbf{6 6}$ led to the product $\mathbf{6 1}$. In similar fashion, reaction of $\mathbf{3 3}$ with $\mathrm{N}$ methylmaleimide afforded 62 in $47 \%$ yield, and reaction of $\mathbf{6 0}$ with $\mathrm{N}$-phenylmaleimide gave $\mathbf{6 3}$ in $42 \%$ yield.

Access to indigo azines was also realized by reaction of $\mathbf{3 9}$ with diethylazodicarboxylate (DEAD). For example, reaction of symmetrically substituted 2,2'-biindole 39 with DEAD at $150{ }^{\circ} \mathrm{C}$ in a sealed tube for $12 \mathrm{~h}$ gave $5,5^{\prime}$-dichloroindigo azine derivative 67 as the only identifiable product in $39 \%$ yield (Scheme 10). Under the identical reaction conditions, reaction of biindole 60 with DEAD afforded 68 in $43 \%$ isolated yield. The isolation of these azine products with the N-sulfonyl group still attached to the indole core indicated that an alternative

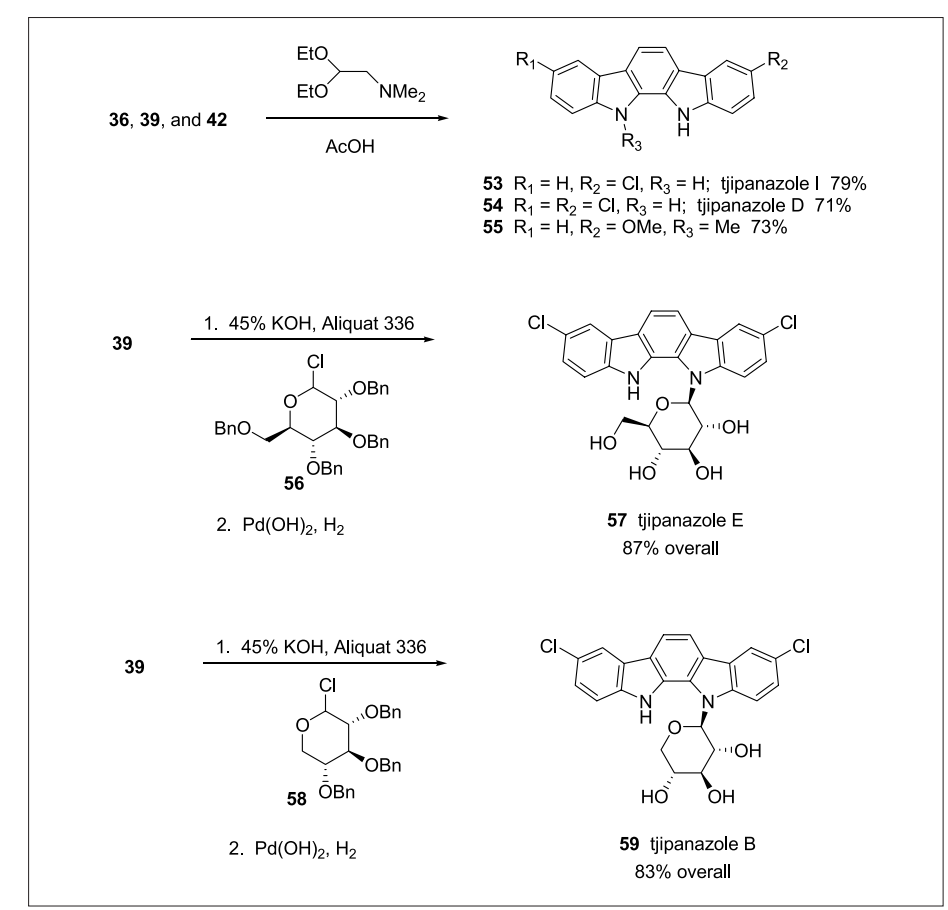

Scheme 8.

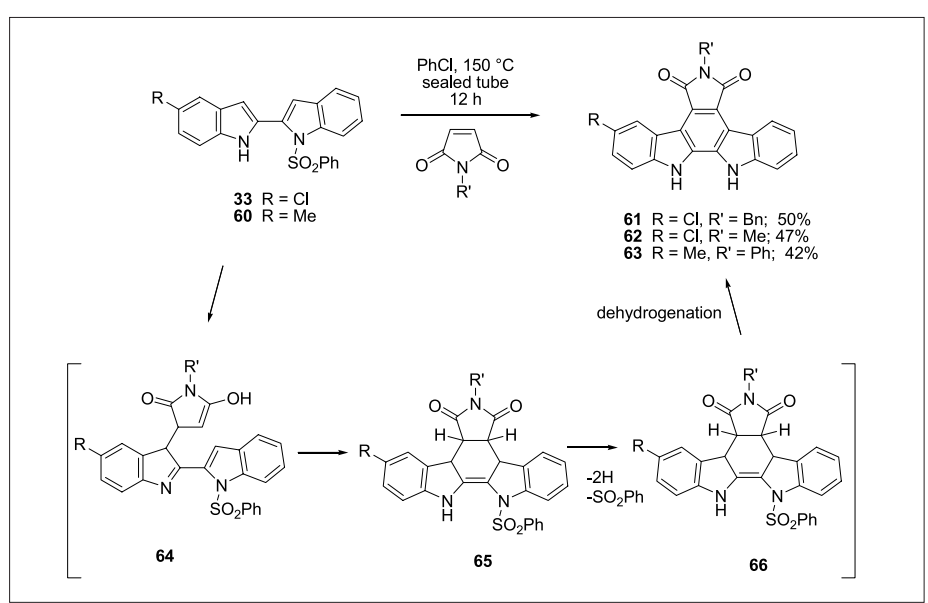

Scheme 9. 


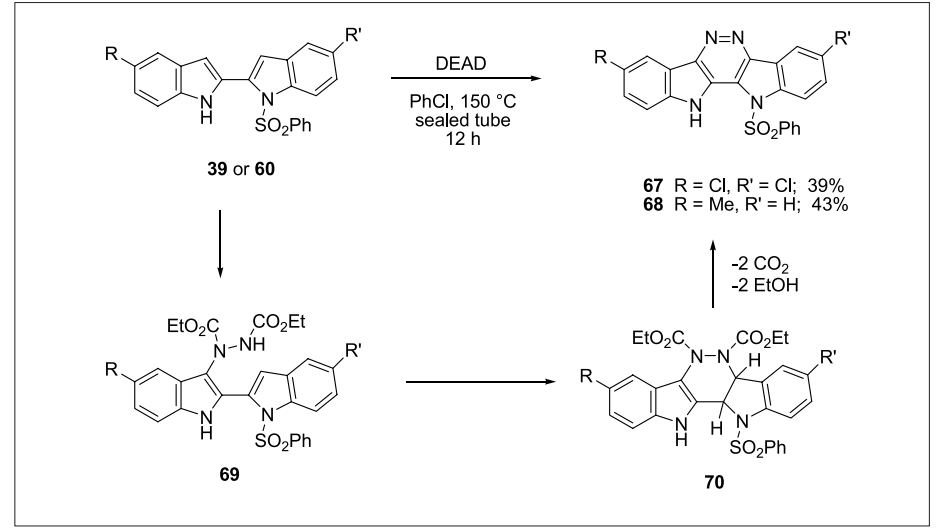

Scheme 10.

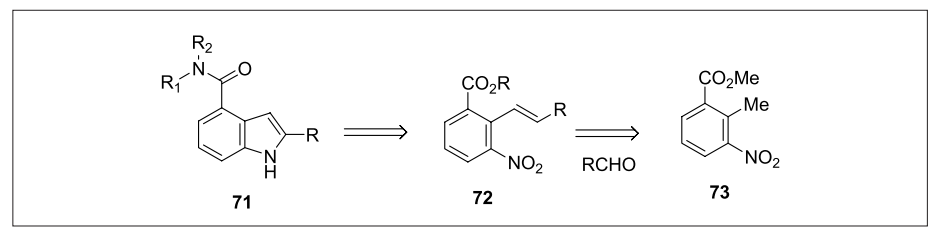

Scheme 11

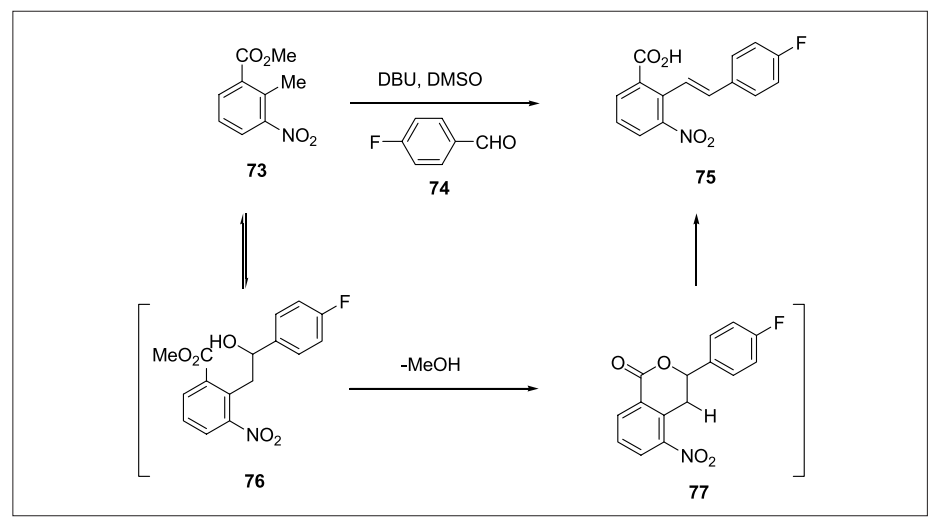

Table 2. Preparation of nitrostyrene benzoic acid derivatives

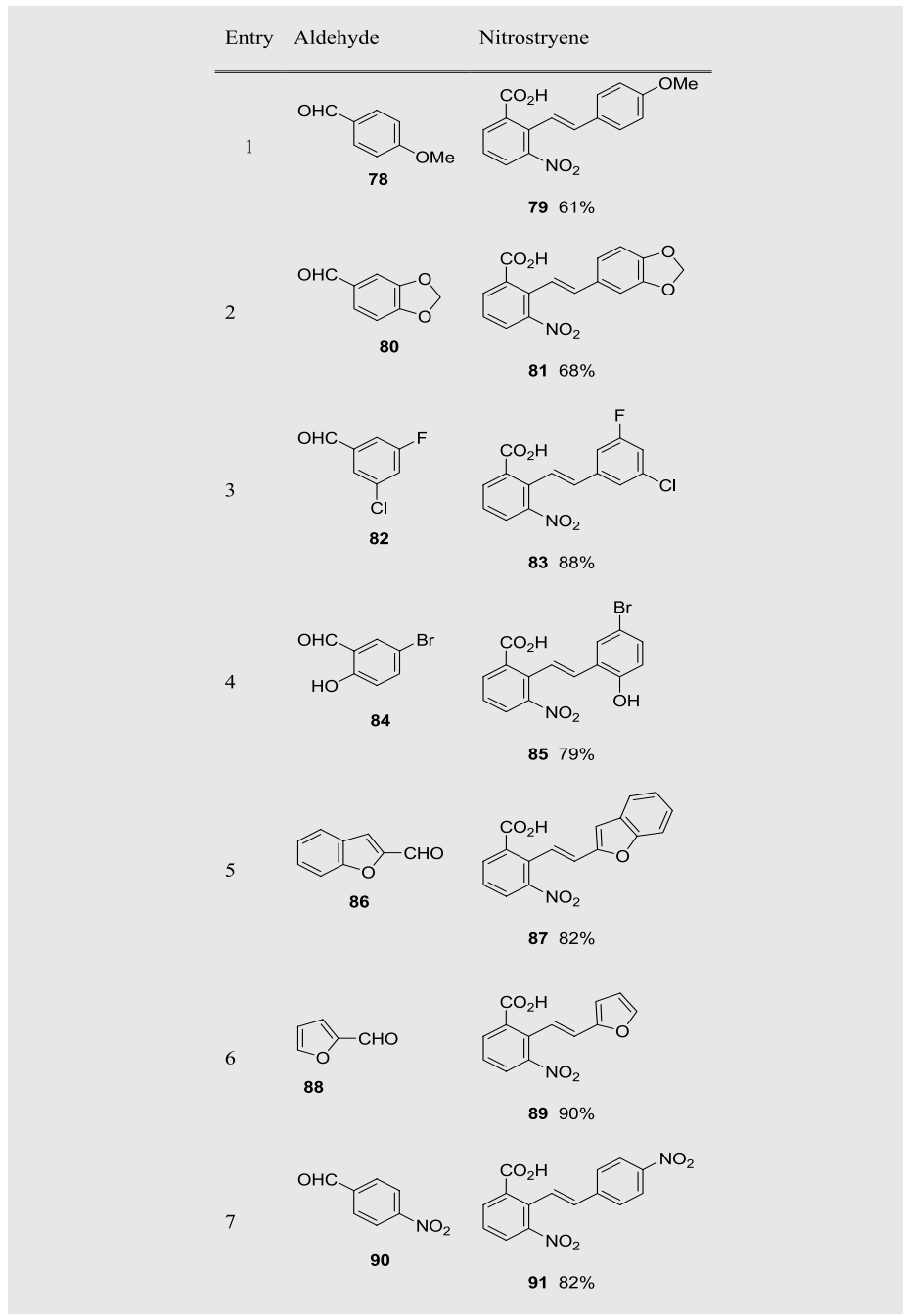

Scheme 12.

reaction mechanism was operating. It was postulated that addition of $\mathbf{3 9}$ to DEAD was followed by rapid re-aromatization of the indole ring to give intermediate 69. Indeed, when the reaction was conducted in toluene for shorter periods of time $(3 \mathrm{~h})$, intermediate 69 could be isolated (56-62\%) and only trace amounts of $\mathbf{6 7}$ were present. Ring closure of 69 to intermediate $\mathbf{7 0}$ leads to aromatization and decarboxylation to give $\mathbf{6 7}$. The primary driving force for the overall sequence from 69 to 67 was aromatization of the C-ring.

\section{Preparation of 2-Arylindole-4- carboxylic Amide Derivatives}

Indole-4-carboxylic amide derivatives possess a wide range of biological activity including $\mathrm{CC}$ chemokine receptor 5 (CCR5) antagonists [39], serotonin (5HT) subtype 2A receptor antagonists [40], muscarinic M2 receptor antagonists [41], bradycardic agents [42], histone deactylase inhibitors [43], p38 $\alpha$ mitogen activated protein kinases (MAPK) inhibitors [44], matrix metalloproteinases (MMPs) inhibitors [45], and poly(ADP-ribose) polymerase-1-inhibitors [46]. Typically indoles of this subclass have been prepared from commercially available indole4-carboxylic acid or 4-bromoindole [47], both of which are expensive reagents and require extensive manipulation if a more substituted pharmacophore is needed. It was recognized that access to indoles of type 71 would feature reaction of commercially available methyl 2-methyl-3-nitrobenzoate $\mathbf{7 3}$ with a substituted aldehyde followed by reductive cyclization (Scheme 11) [48]. Nitrobenzene $\mathbf{7 3}$ was an extremely attractive raw material and would allow for the preparation of indoles of type $\mathbf{7 1}$ in a remarkably straightforward manner.

In order to access indoles of class $\mathbf{7 1}$, an efficient synthesis of nitrostyrenes of type $\mathbf{7 2}$ was imperative. It was previously demonstrated that reaction of ortho-nitrotoluenes with aromatic aldehydes in the presence of DBU in DMSO was a reversible process and only modest to good yields of the corresponding nitro alcohols were obtained [26]. Based on the juxtaposition of the methyl ester with the reacting center and its capacity to serve as an intramolecular electrophilic trap of the intermediate nitro alcohol, reaction of $\mathbf{7 3}$ with aromatic aldehydes was anticipated to lead to the formation of a lactone intermediate (i.e. 77). Reaction of $\mathbf{7 3}$ with 1.5 equiv. of 4-fluorobenzaldehyde $\mathbf{7 4}$ under optimized reaction conditions ( 2 equiv. of DBU, DMSO, $12 \mathrm{~h}$ rt then heat to $50{ }^{\circ} \mathrm{C}$ for $30 \mathrm{~min}$ ) afforded nitrostyrene benzoic acid $\mathbf{7 5}$ in $90 \%$ HPLC assay yield. Under these reaction conditions, none of the intermediate lactone $\mathbf{7 7}$ was observed in the crude reaction mixture. After an extractive workup to remove excess $\mathbf{7 4}$, the product could be obtained in analytically pure form and in $84 \%$ isolated yield by crystallization from $\mathrm{MeOH} /$ water. The overall sequence involved deprotonation of nitrotoluene 73 by DBU followed by addition to $\mathbf{7 4}$ to give nitro alcohol 76, which underwent intramolecular cyclization to lactone 77 (Scheme 12). Further deprotonation of 77 by DBU was followed by elimination of the carboxylate anion to furnish the nitrostyrene benzoic acid product upon workup. This sequence was extremely general and provided access to a structurally diverse array of nitrostyrene benzoic 


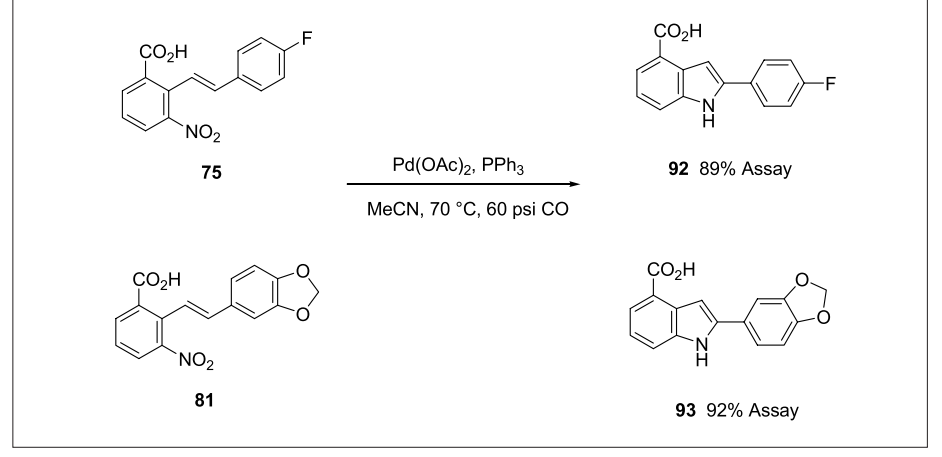

Scheme 13.

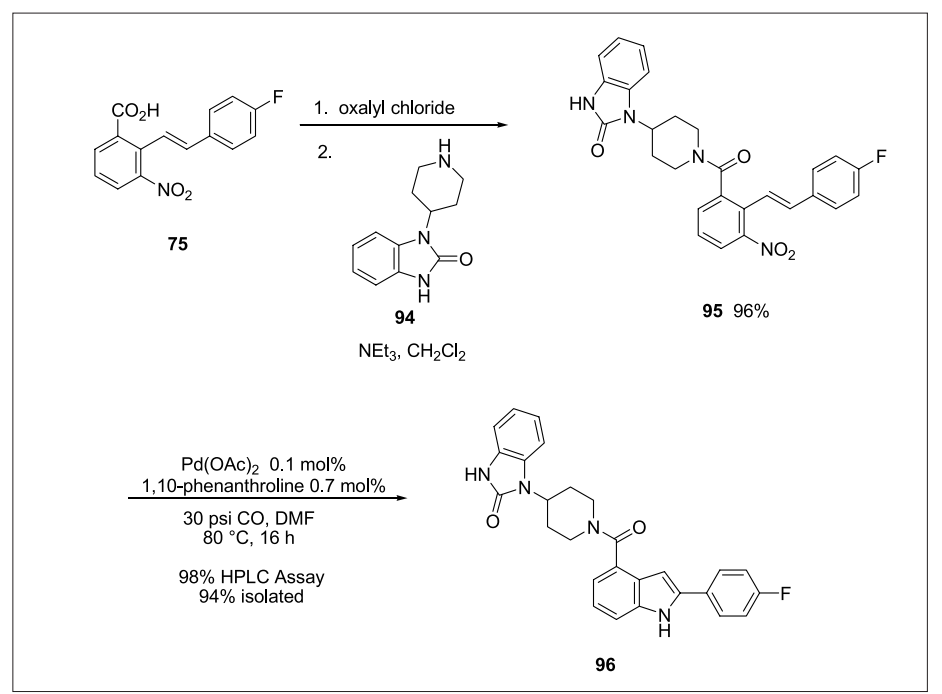

Scheme 14.
Table 3. Preparation of 2-arylindole-4-carboxylic amide derivatives

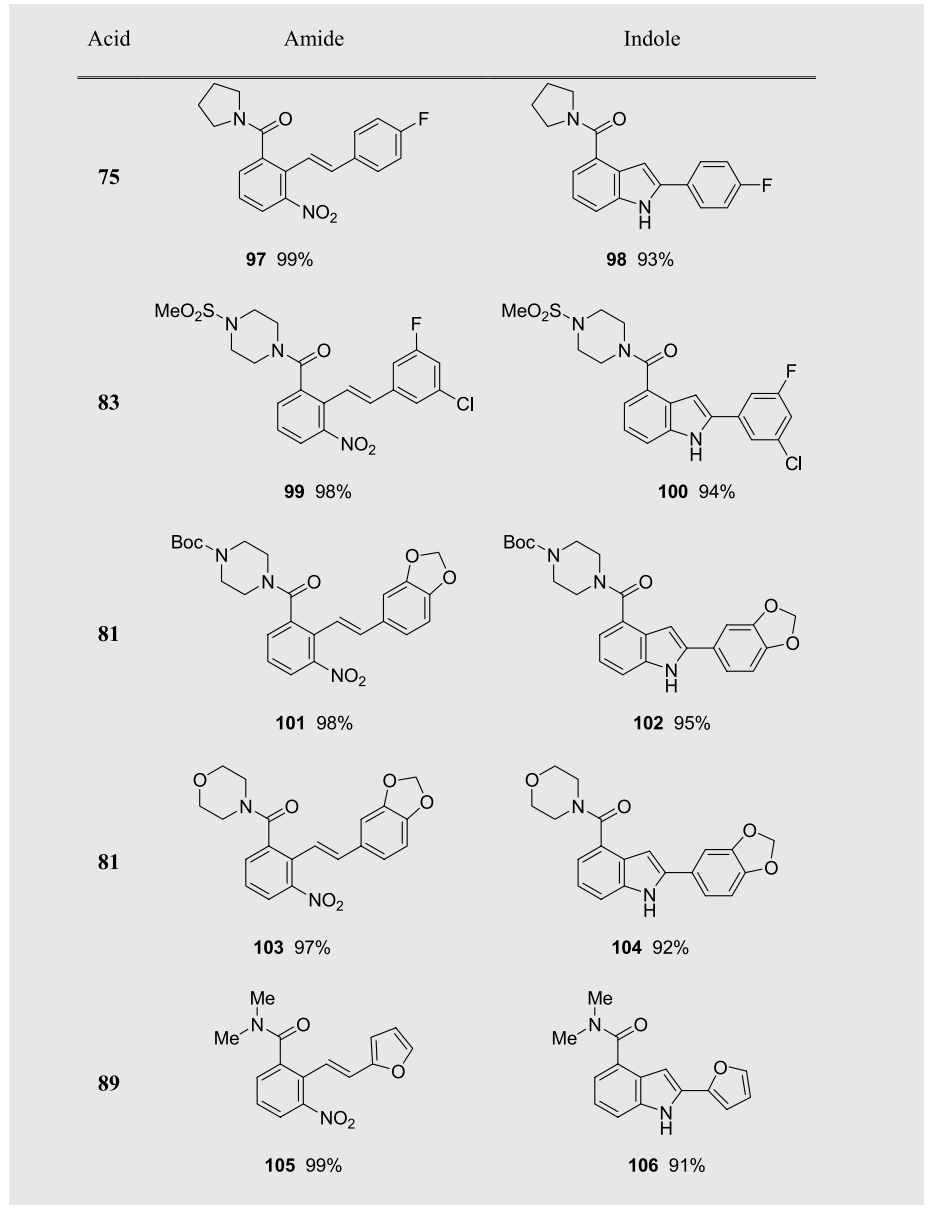

acids in good to excellent yield (Table 2). In addition, the trans-nitrostyrene benzoic acids were the exclusive products with no detectable amounts of the corresponding cis-isomers being formed. Furthermore, electron-donating and electron-withdrawing groups on the aromatic aldehyde participated equally well.

For the preparation of indoles of subclass $\mathbf{7 1}$ bearing an amido-substituent in the four position of the indole ring, a two-step sequence involving either reductive cyclization of the ortho-nitrostyrenes followed by amide formation or amide formation followed by reductive cyclization was required. Initial efforts were focused on reductive cyclization of the nitrostyrene benzoic acids (Scheme 13). For example, reductive cyclization of $\mathbf{7 5}$ and $\mathbf{8 1}$ under the conditions discovered by the Söderberg group [23] (6 mol\% $\mathrm{Pd}(\mathrm{OAc}){ }_{2}, 24 \mathrm{~mol} \% \mathrm{PPh}_{3}$, $\mathrm{MeCN}, 70{ }^{\circ} \mathrm{C}, 60$ psi CO, $16 \mathrm{~h}$ ) afforded indole carboxylic acids $\mathbf{9 2}$ and $\mathbf{9 3}$ in $89 \%$ and $92 \%$ HPLC assay yields, respectively. Unfortunately, the isolation of $\mathbf{9 2}$ and $\mathbf{9 3}$ in pure form was plagued by both solubility issues and the difficulty in removing the excess triphenylphosphine and triphenylphosphine oxide and the isolated yields of $\mathbf{9 2}$ and 93 were $<50 \%$ after crystallization. Due to this difficulty, our attention turned to con- version of the benzoic acid moiety to the required amide functionality prior to reductive cyclization.

Treatment of nitrostyrene benzoic acid 75 with oxalyl chloride in the presence of a catalytic amount of DMF in $\mathrm{CH}_{2} \mathrm{Cl}_{2}$ afforded the intermediate acid chloride which was not isolated (Scheme 14). Reaction with 4-(2-keto-1-benzimidazolinyl)piperazine 94 in the presence of $\mathrm{NEt}_{3}$ gave, after workup, amido nitrostyrene $\mathbf{9 5}$ as a highly crystalline solid and in $96 \%$ isolated yield. Reductive cyclization of $\mathbf{9 5}$ under highly optimized reaction conditions utilized in the KDR program gave indole 96 in $98 \%$ HPLC assay yield. In this case, isolation of 96 was simply a matter of filtration of the catalyst through Celite followed by addition of $1 \mathrm{M} \mathrm{H}_{3} \mathrm{PO}_{4}$ which precipitated the product in analytically pure form and in $94 \%$ isolated yield. The use of $1 \mathrm{M} \mathrm{H}_{3} \mathrm{PO}_{4}$ for the isolation of the product aided in the removal of trace amounts of 1,10-phenanthroline and was mild enough that sensitive functionalities such as a Boc-protecting group were preserved (Table 3 , entry 3 ). The sequence whereby the appropriately substituted nitrostyrene benzoic acid was converted to an amide followed by reductive cyclization provided an extremely high yielding means of preparing a diverse array of highly functionalized 'drug-like' 2-arylindole-4-carboxylic amides (Table 3.)

\section{Preparation of $\mathrm{N}-\mathrm{Hydroxyindoles}$}

$\mathrm{N}$-Hydoxyindoles and their derivatives have received considerable attention in recent years [49]. The biological role of $\mathrm{N}$-hydroxyindoles is still an area of active investigation since they have been shown to possess biological activity in certain cases. In addition, biologically inactive indoles have been rendered biologically active when their N-hydroxyindole analogues were examined. The preparation of N-hydroxyindoles has been somewhat limited by currently available methods for their preparation which suffer from low yields and competing side reactions. Even though the Somei 'tungstate method' [50] has addressed some of these limitations, the ability to assemble highly functionalized $\mathrm{N}$ hydroxyindoles rapidly from simple precursors prompted our investigations in this area [51]. It was envisioned that reductive cyclization of suitably substituted orthonitrobenzyl ketone would be an attractive method for their preparation.

Although the reductive cyclization of ortho-nitrobenzyl ketones or aldehydes to 


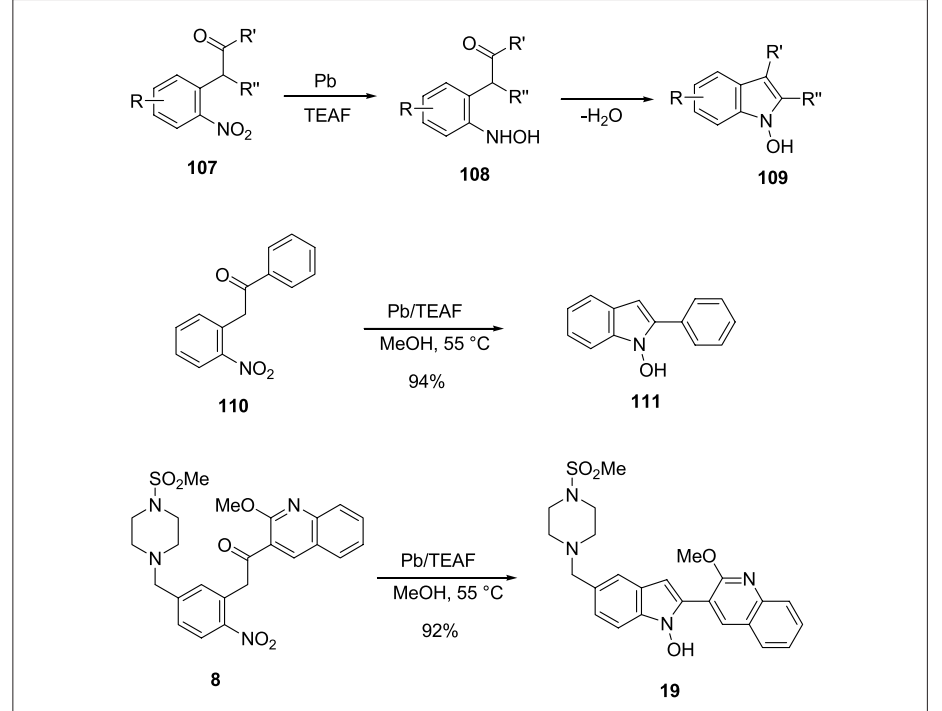

Scheme 15.

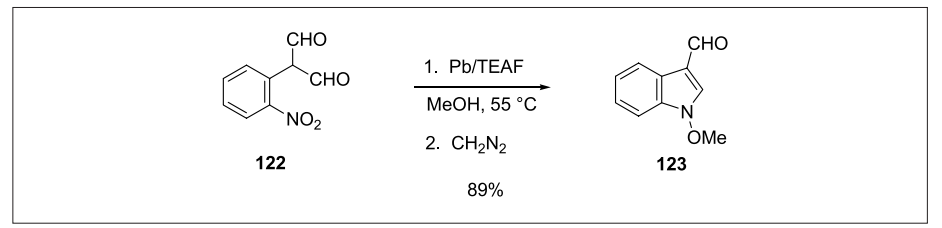

Scheme 16.
Table 4. Preparation of $\mathrm{N}$-hydroxyindoles

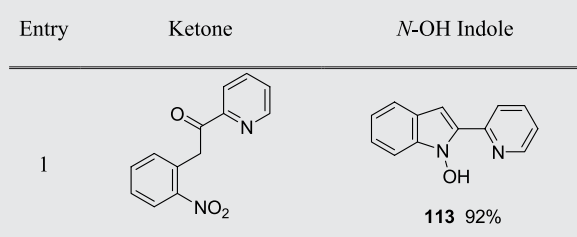

112
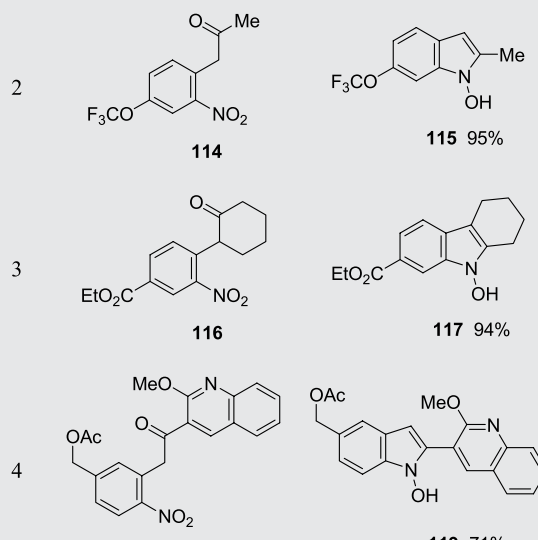

118

$11971 \%$

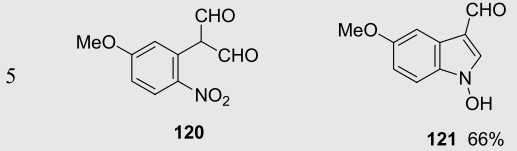

N-hydroxyindoles have been reported under a variety of conditions [52], these reaction conditions were generally intolerable to many functional groups, low yielding, and substrate limited. In many cases, further reduction of the N-hydroxyindole products to the corresponding indoles was competitive giving rise to multiple reaction products. Inspired by an observation of Gowda, who reported the reduction of nitro compounds to azo derivatives with $\mathrm{Pb} /$ triethylammonium formate (TEAF) [53], we envisioned that capture of the intermediate N-hydroxyaniline 108 by an adjacent carbonyl would provide N-hydroxyindoles $\mathbf{1 0 9}$ in a straightforward manner (Scheme 15).

Treatment of nitroketone 110 [54] with $\mathrm{Pb} / \mathrm{TEAF}$ in $\mathrm{MeOH}$ at $55{ }^{\circ} \mathrm{C}$ for 12 $\mathrm{h}$ gave 2-phenyl-N-hydroxyindole $\mathbf{1 1 1}$ as the sole reaction product which was isolated in $94 \%$ yield. There was no detectable amount of 2-phenylindole in the crude reaction mixture as evidenced by both HPLC and NMR. When the highly functionalized intermediate $\mathbf{8}$ which was utilized in the synthesis of KDR kinase inhibitor 1 was subjected to the identical reaction conditions, N-hydroxyindole 19 was obtained in $92 \%$ yield. This method proved to be extremely general and allowed for the preparation of a number of substituted $\mathrm{N}$-hydroxyindoles in good to excellent yield (Table 4). In all cases, isolation of the products was achieved by filtration of the insolubles, concentration of the solvent, and filtration through a small plug of silica gel to afford the products as stable crystalline solids.

The methodology was further highlighted by the two-step preparation of 1methoxyindole-3-carboxaldehyde 123, a natural product isolated from the Cruciferae family of plants and extensively utilized as a building block for the synthesis of other natural products (Scheme 16) [55][56]. Lead-promoted reductive cyclization of commercially available 2-nitromalondialdehyde $\mathbf{1 2 2}$ was followed by methylation of the corresponding N-hydroxyindole with $\mathrm{CH}_{2} \mathrm{~N}_{2}$ and afforded $\mathbf{1 2 3}$ in $89 \%$ overall yield. Although this methodology utilizes stoichiometric lead, the rapid assembly of the product $N$-hydroxyindoles coupled with the fact that the products are obtained essentially lead-free renders this approach particularly attractive.

\section{Preparation of 2-Aryl-5- Substituted-2,3-Dihydrobenzofurans}

The 2,3-dihydrobenzofuran ring system constitutes the core skeleton of an increasing number of neolignan natural products that possess a range of biological activity [57]. In addition, 2,3-dihydrobenzofurans have been developed for treatment of traumatic and ischemic CNS injury [58], and are reported to be useful in the treatment of arteriosclerosis, hepatopathy, and cerebrovasculary disease [59]. While there are a multitude of methods for the preparation of 2,3-dihydrobenzofurans, strategies which provide rapid access to the 2,3-dihydrobenzofuran ring system not accessible through current synthetic techniques are invaluable. Our approach was guided by the work of Bartoli and our own related work with nitrotoluenes. Bartoli discovered that reaction of 4-cyano-1nitro-2-[(trimethylsilyl)-methyl]benzene (124) with benzaldehyde in the presence of an equimolar amount of TBAF gave 5-cyano-2,3-dihydro-2-phenylbenzofuran 125 in $70 \%$ yield [19]. Based on our own observations, it was apparent that TBAF might be basic enough to promote the direct formation of the expected tetrabutylammonium alkoxide intermediate 126 from unfunctionalized ortho-nitrotoluenes $\mathbf{1 2 7}$. The direct use of simple and often commercially available ortho-nitrotoluenes for the preparation of highly substituted 2,3dihydrobenzofurans would greatly simplify the Bartoli two-step protocol. It was against this background that a thorough investigation of the Bartoli methodology utilizing ortho-nitrotoluenes was initiated [60].

After extensive reaction optimization, it was discovered that reaction of a mixture of nitrotoluene 127a and aldehyde 11 in the presence of 1.5 equiv. of TBAF and 2 equiv. of Hünig's base in refluxing THF for $3 \mathrm{~h}$ furnished 2,3-dihydrobenzofuran 128 in $69 \%$ yield (Scheme 17). The use of Hünig's base served to remove the liberated HF from the reaction mixture and was cru- 


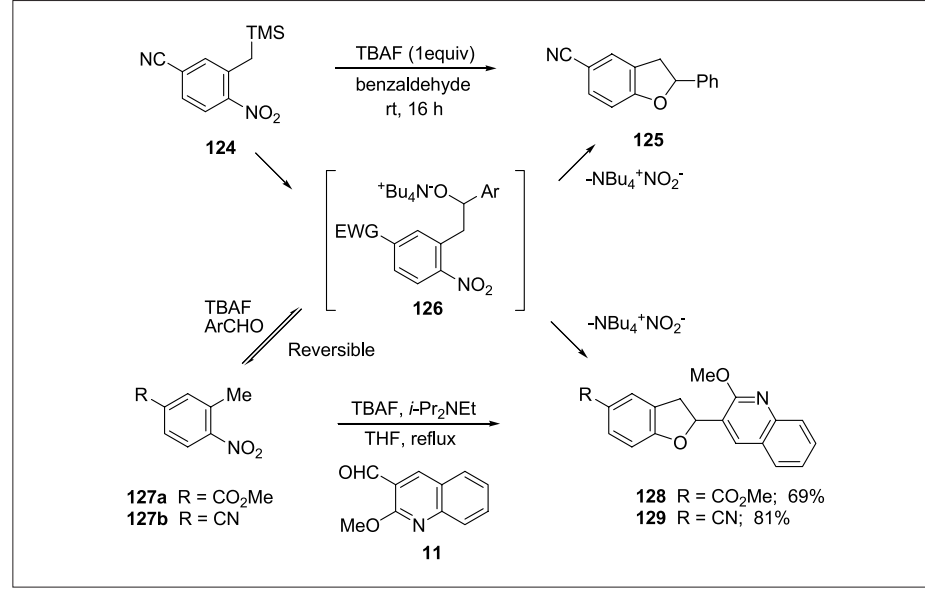

Scheme 17.

Table 5. Preparation of 2,3-dihydrobenzofurans

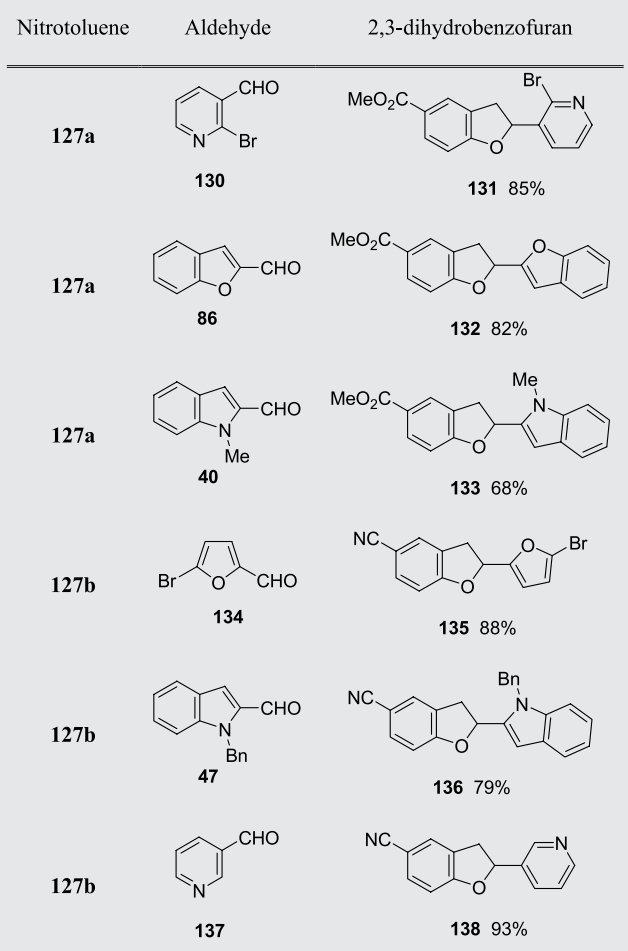

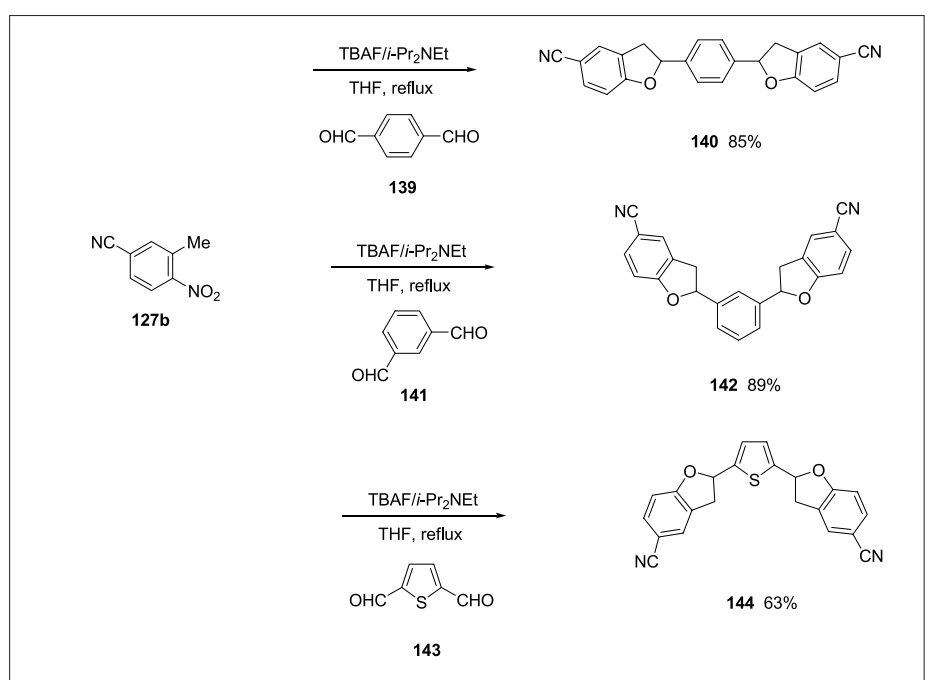

Scheme 18.

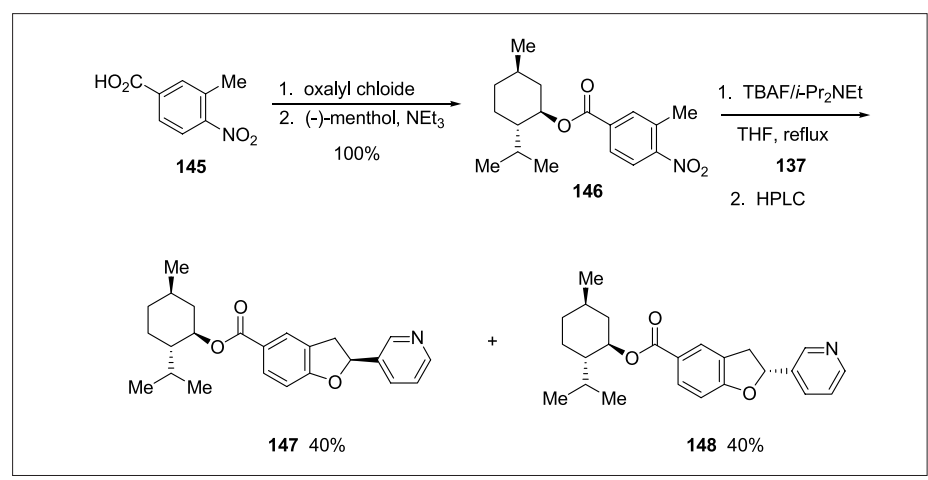

Scheme 19. cial for obtaining high yields. In addition, the addition of 127a to aldehyde 11 was observed to be reversible; however, conducting the reaction in refluxing THF drives the reaction to completion in several hours. In similar fashion, reaction of $\mathbf{1 2 7} \mathbf{b}$ with $\mathbf{1 1}$ provided 129 in $81 \%$ yield. The one-pot operation was general and provided access to a structurally diverse array of substituted 2,3-dihydrobenzofurans in good to excellent yields (Table 5).

This methodology was also successfully applied toward the synthesis of dimeric 2,3dihydrobenzofurans as outlined in Scheme 18 [61]. For example, reaction of 2 equiv. of $127 \mathrm{~b}$ with terephthalaldehyde 139 gave dimer 140 that crystallized from the crude reaction mixture in analytically pure form and in $85 \%$ isolated yield. In like fashion, reaction of 127b with isophthalaldehyde 141 or 2,5-thiophenedicarboxaldehyde 143 afforded dimers 142 and 144 in $89 \%$ and $63 \%$ yields, respectively.

Due to the reversibility of the process, the methodology does not lend itself to the one-pot asymmetric synthesis of 2,3dihydrobenzofurans. However, chiral 2,3dihydrobenzofurans are obtained in just three steps by using (-)-menthol as a chiral auxiliary (Scheme 19) [61]. For example, preparation of menthyl ester 146 (100\%) was followed by treatment with TBAF in the presence of aldehyde $\mathbf{1 3 7}$ and gave a 1:1 mixture of $147(40 \%)$ and $148(40 \%)$. The individual diastereomers were then separated by HPLC. Thus chiral 2,3-dihydrobenzofurans are also accessible through this methodology involving readily available benzoic acid 145, (-)-menthol, and an appropriately substituted aldehyde fol- lowed by chromatography of the individual diastereomers by HPLC.

\section{Conclusions}

The novel methodology discovered in the development of the long-term manufacturing route of KDR kinase inhibitor $\mathbf{1}$ has led to a successful research program aimed at taking advantage of the underlying versatility of nitrobenzenes. The use of readily available nitrobenzene and nitrotoluene compounds for the rapid construction of highly functionalized indoles and 2,3-dihydrobenzofurans is an extremely powerful method that will continue to see growth as a practical and efficient means of preparing these highly valued pharmacophores. The addition of trimethylsilyl nitro compounds 
and ortho-nitrotoluenes to various aromatic aldehydes provides an intermediate alcohol which can either be oxidized to the corresponding nitroketone or undergo elimination to a nitrostyrene. Palladium-catalyzed reductive cyclization of these intermediates leads to substituted indoles. In certain cases, the intermediate nitroalcohol can be trapped leading to 4-substituted nitrostyrene benzoic acids and 2,3-dihydrobenzofurans. Often the products are obtained in a minimal number of synthetic transformations and generally do not require the use of chromatography. Due to the extremely low catalyst/ligand loadings for many of the nitrostyrene reductive cyclizations, final API products can generally be isolated with low levels of residual palladium $(<20$ ppm). In addition, these methodologies are exceptionally mild and tolerant of a wide range of functional groups. Potential applications to parallel and diversity oriented synthesis are also possible.

\section{Acknowledgments}

The author would like to thank the many coworkers whose names appear in the appropriate references that contributed to this work. The author would also like to thank Dr. Kevin Campos and Dr. Guy Humphrey of Merck \& Co., Inc for careful review of the manuscript.

Received: July 15, 2006

[1] a) R.J. Sundberg, 'The Chemistry of Indoles', Academic Press: New York, 1970; b) R.J. Sundberg, 'Pyrroles and Their Benzoderivatives: Synthesis and Applications', in 'Comprehensive Hetereocyclic Chemistry', Eds. A.R. Katritzky, C.W. Rees, Pergamon: Oxford, U.K., 1984, Vol. 4, pp 313-376; c) R.J. Sundberg, in 'Best Synthetic Methods, Indoles', Academic Press: New York, 1996, pp 7-11; d) J.A. Joule, 'Indole and its Derivatives', in 'Science of Synthesis: Houben-Weyl Methods of Molecular Transformation', Ed. E.J. Thomas, George Thieme Verlag: Stuttgart, Germany, 2000, Category 2, Vol. 10, Chapter 10.13; e) R.K. Brown, in 'Indoles', Ed. W.J. Houlihan, Wiley-Interscience: New York, 1972; f) R.J. Sundberg, in 'Comprehensive Heterocyclic Chemistry II', Eds. A.R. Katritzky, C.W. Rees, E.F.V. Scriven, C.W. Bird, Pergamon Press: Oxford, 1996, Vol. 2, p 119; g) G.W. Gribble, in 'Comprehensive Heterocyclic Chemistry II', Eds. A.R. Katritzky, C.W. Rees, E.F.V. Scriven, C.W. Bird, Pergamon Press: Oxford, 1996, Vol. 2, p 207; h) 'Indoles', Ed. R.J. Sundberg, Acedemic Press: London, 1996.

[2] a) B.E. Evans, K.E. Rittle, M.G. Bock, R.M. DiPardo, R.M. Fridinger, W. L. Whitter, G.F. Lundell, D.F. Verber, P.S. Anderson, R.S.L. Chang, V.J. Lotti, D.H. Cerino, T.B. Chen, P.J. Kling, K.A. Kinkel, J.P. Springer, J. Hirshfield, J. Med. Chem. 1988, 31, 2235; b) D.A. Horton,
G.T. Bourne, M.L. Smythe, Chem. Rev. 2003, 103, 893 and references therein.

[3] G.R. Humphrey, J.T. Kuethe, Chem. Rev. 2006, 106, 2875.

[4] For other reviews on the synthesis of indoles, see: a) G.W. Gribble, J. Chem. Soc., Perkin Trans. 1 2000, 1045; b) U. Pindur, R. Adam, J. Heterocycl. Chem. 1988, 25, 1; c) T.L. Gilchrist, J. Chem. Soc., Perkin Trans. 1 2001, 2491.

[5] a) P. Carmeliet, R.K. Jain, Nature 2000, 407, 249; b) J. Folkman, Nature Med. 1995, 1, 27; c) J. Folkman, N. Engl. J. Med. 1995, 333, 1757; c) P. Traxler, Expert Opin. Ther. Targets 2003, 7, 215 and references therein.

[6] a) D. De-Feo-Jones, D.C. Helmbrook, R.E. Jones, U.S. Patent Appl. US2002/0041880 A1, 2000; b) M.E. Fraley, K.L. Arrington, M.T. Bilodeau, G.A. Hartman, W.F. Hoffman, Y. Kim, R.W. Hungate, U.S. Patent, 6306874 B1, 2001; c) Merck \& Co., Inc. World Intellectual Property Organization Patent WO 087651, 2004.

[7] M.E. Fraley, W.F. Hoffman, K.L. Arrington, R.W. Hungate, G.D. Hartman, R.C. McFall, K.E. Coll, K. Rickert, K.A. Thomas, G.B. McGraughey, Curr. Med. Chem. 2004, 11, 709 .

[8] a) C.N. Johnson, G. Stemp, N. Anand, S.C. Stephen, T. Gallagher, Synlett 1998, 1025; b) B. Danieli, G. Lesma, M. Martinelli, D. Passarell, I. Perettlo, A. Silvani, Tetrahedron 1998, 54, 14081; c) T.D. Krizan, J.C. Martin, J. Am. Chem. Soc. 1983 , 105, 6155; d) S. Caron, J.M. Hawkins, J. Org. Chem. 1998, 63, 2054; e) T. Hiyama, in 'Metal-Catalyzed Cross-Coupling Reactions' Eds. F. Diederich, P.J. Stang, Wiley-VCH, Weinheim, Germany, 1988 ; Chap. 10; f) K. Tamao, K. Kobayashi, Y. Ito, Tetrahedron Lett. 1989, 30, 6051; g) M. Mowery, P. DeShong, J. Org. Chem. 1999, 64, 1648; h) M.H. Lee, S.P. Nolan, Org. Lett. 2000, 2, 2053; i) S.E. Denmark, D. Wehrli, Org. Lett. 2000, 2, 565; j) S.E. Denmark, L. Neuville, Org. Lett. 2000, 2 , 3221; k) S.E. Denmark, W. Pan, Org. Lett. 2001, 3, 61; 1) S.E. Denmark, J.D. Baird, Org. Lett. 2004, 6, 3649.

[9] E. Vazquez, I.W. Davies, J.F. Payack, J. Org. Chem. 2002, 67, 7551.

[10] J.F. Payack, E. Vazquez, L. Matty, M. H. Kress, J. McNamara, J. Org. Chem. 2005 , $70,175$.

[11] J.T. Kuethe, A. Wong, C. Qu, J. Smitrovich, I. W. Davies, D.L. Hughes, J. Org. Chem. 2005, 70, 2555.

[12] J.L. Rutherford, M.P. Rainka, S.L. Buchwald, J. Am. Chem. Soc. 2002, 124, 15168.

[13] T. Iwama, V.B. Birman, S.A. Kozmin, V.H. Rawal, Org. Lett. 1999, 1, 673.

[14] a) T.V. RajanBabu, G.S. Reedy, T. Fukunaga, J. Am. Chem. Soc. 1985, 107, 5473; b) T.V. RajanBabu, B.L. Chenard, M.A. Petti, J. Org. Chem. 1986, 51, 1704.

[15] M.G. Banwell, B.D. Kelly, O.J. Kokas, D.W. Lupton, Org. Lett. 2003, 5, 2497.
[16] A. Ricci, M. Fochi, Angew. Chem. Int. Ed. 2003, 42, 1444 and references therein

[17] R.M. Jacob, German Patent DE 828695, 1950.

[18] G. Bartoli, M. Bosco, D. Caretti, R. Dalpozzo, R.E. Todesco, J. Org. Chem. 1986 , $51,3694$.

[19] G. Bartoli, M. Bosco, D. Caretti, R. Dalpozzo, R.E. Todesco, J. Org. Chem. 1987 , $52,4381$.

[20] a) J.D. Albright, L. Goldman, J. Am. Chem. Soc. 1965, 87, 4214; b) J.D. Albright, L. Goldman, J. Am. Chem. Soc. 1967, 89, 2416.

[21] A. Wong, J.T. Kuethe, I.W. Davies, D.L. Hughes, J. Org. Chem. 2004, 69, 7761.

[22] a) R.J. Sundberg, J. Org. Chem. 1965, 30, 3604; b) R.J. Sundberg, T. Yamazaki, J. Org. Chem. 1967, 32, 290; c) P.M. Fresneda, P. Molina, S. Delgado, Tetrahedron 2001, 57, 6197.

[23] For leading references, see: a) S.W. Dantale, B.C.G. Söderberg, Tetrahedron $\mathbf{2 0 0 3}$, 59, 5507; b) T.L. Scott, B.C.G. Söderberg, Tetrahedron Lett. 2002, 43, 1621; c) B.C.G. Söderberg, J.A. Shriver, J. Org. Chem. 1997, 62, 5838; d) B.C. Söderberg, S.R. Rector, S.N. O'Neil, Tetrahedron Lett. 1999, 40, 3657.

[24] a) J.I.G. Cadogan, M. Cameron-Wood, Proc. Chem. Soc. 1962, 361; b) J.I.G. Cadogan, R.K. Mackie, M.J. Todd, J. Chem. Soc., Chem. Commun. 1966, 491.

[25] a) R.J. Sundberg, J. Org. Chem. 1965, 30, 3604; b) R.J. Sundberg, T. Tamazaki, J. Org. Chem. 1967, 32, 290.

[26] I.W. Davies, J.H. Smitrovich, R. Sidler, C. Qu, V. Gresham, C. Bazaral, Tetrahedron 2005, 61, 6425 .

[27] For reviews, see: a) B.C.G. Söderberg, Curr. Org. Chem. 2000, 4, 727; b) P.G. Tsoungas, A.I. Diplas, Curr. Org. Chem. 2004, 8,1579 .

[28] J.T. Kuethe, A. Wong, I.W. Davies, Org. Lett. 2003, 5, 3975.

[29] H. Horstmann, P. Andrews, R. Goennert, Eur. J. Med. Chem. 1980, 15, 399.

[30] For leading references, see: a) J. Bergman, T. Janosik, N. Wahlström, Adv. Heterocycl. Chem. 2001, 80, 1; b) U. Pindur, Y.-S. Kim, Curr. Med. Chem. 1999, 6, 29; c) J. Bergman, Stud. Nat. Prod. Chem., A 1988, 1, 3; d) W. Steglich, Fortschr. Chem. Org. Naturst. 1987, 51, 216; e) G.W. Gribble, S.J. Berthel, Stud. Nat. Prod. Chem. 1993, 12, 365; f) M. Prudhomme, Curr. Pharm. Design 1997, 3, 265.

[31] a) T. Tamaoki, H. Nomoto, I. Takahishi, Y. Kato, M. Morimoto, F. Tomita, Biochem. Biophy. Res. Commun. 1986, 135, 397; b) S. Omura, Y. Sasaki, T. Iwai, H. Takashima, J. Antibiot. 1995, 48, 535.

[32] M.J. Slater, S. Cockerill, R. Baxter, R.W. Bonser, K. Gohil, C. Gowrie, J.E. Robinson, E. Littler, N. Parry, R. Randall, W. Snowden, Bioorg. Med. Chem. 1999, 7 , 1067.

[33] J.T. Kuethe, A. Wong, I.W. Davies, Org. Lett. 2003, 5, 3721. 
[34] For the synthesis of substituted indolocarbazoles from 2,2'-biindoles, see: a) J.L. Wood, B.M. Stoltz, H.-J. Dietich, J. Am. Chem. Soc. 1995, 117, 10413; b) J.L. Wood, B.M. Stoltz, H.-J. Dietrich, D.A. Pflum, D.T. Petsch, J. Am. Chem. Soc. 1997, 119, 9641.

[35] T. Janosik, J. Bergman, Tetrahedron 1999, $55,2371$.

[36] A. Akao, S. Hiraga, T. Iida, A. Kamatani, M. Kawasaki, T. Mase, T. Nemoto, N, Satake, S.A. Weissman, D.M. Tschaen, K. Rossen, D. Petrillo, R.A. Reamer, R.P. Volante, Tetrahedron 2001, 57, 8917.

[37] T. Iversen, D.R. Bundle, Carbohydr. Res. 1982, 103, 29.

[38] J.T. Kuethe, I.W. Davies, Tetrahedron Lett. 2004, 45, 4009.

[39] G. Thoma, F. Nuninger, M. Schaefer, K.G. Akyel, R. Albert, C. Beerli, C. Bruns, E. Francotte, M. Luyten, D. MacKenzie, L. Oberer, M.B. Streiff, T. Wagner, H. Walter, G. Weckbecker, H.-G. Zerwes, J. Med. Chem. 2004, 47, 1939.

[40] K. Kumar, D. Michalik, I.G. Castro, T. Tillack, A. Zapf, M. Arlt, T. Heinrich, H. Boettcher, M. Beller, Chem. Eur. J. 2004, 10, 746.

[41] A. Palani, S. Dugar, J.W. Clader, W.J. Greenlee, V. Ruperto, R.A. Duffy, J.E. Lachowicz, Bioorg. Med. Chem. Lett. 2004, 14, 1791.

[42] A. Kakefuda, T. Watanabe, Y. Taguchi, N. Masuda, A. Tanaka, I. Yanagisawa, Chem. Pharm. Bull. 2003, 51, 390.

[43] Y. Dai, Y. Guo, J. Guo, L.J. Pease, J. Li, P.A. Marcotte, K.B. Glaser, P. Tapang, D.H. Albert, P.L. Richardson, S.K. Davidsen, M.R. Michaelides, Bioorg. Med. Chem. Lett. 2003, 13, 3087.

[44] B.J. Mavunkel, S. Chakravarty, J.J. Perumattam, G.R. Luedtke, X. Liang, D. Lim, Y.-J. Xu, M. Laney, D.Y. Liu, G.F. Schreiner, J.A. Lewicki, S. Dugar, Bioorg. Med. Chem. Lett. 2003, 13, 3087.

[45] A.-M. Chollet, T.L. Diguarher, N. Kucharczyk, A. Loynel, M. Bertrand, G. Tucker, N. Guilbaud, M. Burbridge, P. Pastoureau, A. Fradin, M. Sabatini, J.-L. Fauchère, P. Casara, Bioorg. Med. Chem. Lett. 2002, 10, 531 .

[46] S.S.C. Koch, L.H. Thoresen, J.G. Tikhe, K.A. Maegley, R.J. Almassy, J. Li, X.-H. Yu, S.E. Zook, R.A. Kumpf, C. Zhang, T.J. Boritzki, R.N. Mansour, K.E. Zhang, A. Ekker, C.R. Calabrese, N.J. Curtin, S. Kyle, S.E. Thomas, L.-Z. Wang, A.H. Calvert, B.T. Golding, R.J. Griffin, D.R. Newell, S.E. Webber, Z. Hostomsky, J. Med. Chem. 2002, 45, 4961.

[47] For leading references, see: K. Kumar, A. Zapf, D. Michalik, A. Tillack, T. Heinrich, H. Böttcher, M. Arlt, M. Beller, Org. Lett. 2004, 6, 7 and references cited therein.

[48] J.T. Kuethe, I.W. Davies, Tetrahedron 2006, 62, doi: 10.1016/j.tet.2006.05.007.

[49] For reviews on N-hydroxyindoles and their derivatives, see: a) M. Somei, $A d v$.
Heterocycl. Chem. 2002, 82, 101; b) M. Somei, Heterocycles 1999, 50, 1157; c) R.M. Acheson, Adv. Heterocycl. Chem. 1990, 51, 105; d) M. Somei, Yuki Gosei Kogaku Kyokaishi 1991, 49, 205; e) R.M. Acheson, in 'New Trends in Heterocyclic Chemistry' Eds. R.B. Mitra, N.R. Ayyanger, Y.N. Gogte, R.M. Acheson, N. Cromwell, Elsevier Science Publishers: New York, 1979; p. 1.

[50] a) M. Somei, T. Kawasaki, Heterocycles 1989, 29, 1251; b) T. Kawasaki, A. Kodama, T. Nishida, K. Shimizu, M. Somei, Heterocycles 1991, 32, 221.

[51] A. Wong, J.T. Kuethe, I.W. Davies, J. Org. Chem. 2003, 68, 9865.

[52] See ref. [49] and references cited therein.

[53] G.R. Srinivasa, K. Abiraj, D.C. Gowda, Tetrahedron Lett. 2003, 44, 5835.

[54] P. Strazzolini, A.G. Giumanini, A. Runcio, M. Scuccato, J. Org. Chem. 1998, 63, 952.

[55] For the isolation of 123, see: K. Monde, M. Takasugi, A. Shirata, Phytochemistry 1995, 39, 581.

[56] For the use of $\mathbf{1 2 3}$ in natural product synthesis, see a) ref. [47]; b) M. Somei, H. Ohnishi, Y. Shoken, Chem. Pharm. Bull. 1986, 34, 677; c) R.M. Acheson, P.G. Hunt, D.M. Littlewood, B.A. Murrer, H.E. Rosenburg, J. Chem. Soc., Perkin Trans. 1 1978, 1117.

[57] a) B.J. Donnelly, M.X. Donnelly, A.M. O'Sullivan, J.P. Prendergast, Tetrahedron 1969, 25, 4409; b) T. Hayashi, R.H. Thomson, Phytochemistry 1975, 14, 1085; c) M. Gregson, W.D. Ollis, B.T. Redman, I.O. Sutherland, H.H. Dietrichs, O.R. Gottlieb, Phytochemistry 1978, 17, 1395; d) R.S. Ward, Nat. Prod. Rep. 1995, 12, 183; e) R.S. Ward, Nat. Prod. Rep. 1997, 14, 43; f) P.J.C. Benevides, P. Sartorelli, M.J. Kato, Phytochemistry 1999, 52, 339; g) I.R. Nascimento, L.M.X. Lopes, Phytochemistry 1999, 52, 345; h) M. Gordaliza, M. Castro, J.M. Corral, M. LopezVazquez, A.S. Feliciano, G.T. Faircloth, Bioorg. Med. Chem. Lett. 1997, 7, 2781; i) I.-L. Tsai, C.-F. Hsieh, C.-Y. Duh, Phytochemistry 1998, 48, 1371; j) C.-H. Chen, C.-Y. Shaw, C.-C. Chen, T.-C. Tsai, J. Nat. Prod. 2002, 65, 740; k) S. Apers, D. Paper, J. Bürgermeister, S. Baronikova, S. Van Dyck. G. Lemière, A. Vlietinck, L. Pieters, J. Nat. Prod. 2002, 65, 718; 1) P. Satorelli, P.J.C. Benevides, R.M. Ellensohn, M.V.A.F. Rocha, P.R.H. Moreno, M.J. Kato, Plant Sci. 2001, 161, 1083.

[58] S. Ohkawa, K. Fukatsu, S. Miki, T. Hashimoto, J. Sakamoto, T. Doi, Y. Nagai, T. Aono, J. Med. Chem. 1997, 40, 559.

[59] T. Aono, S. Ohkawa, T. Doi, EP Patent 483772, 1992.

[60] J.T. Kuethe, A. Wong, M. Journet, I.W. Davies, J. Org. Chem. 2005, 70, 3727

[61] Unpublished results from the Author. 